http://dx.doi.org/10.30681/23588403v11i013246

\title{
IMPRENSA VIRTUAL: DEZ PALAVRAS ABRINDO UM DEBATE NA LINGUAGEM
}

Data de recebimento: $19 / 11 / 2017$

Aceite: 05/12/2017

\author{
Rayani Andressa da Cruz OLIVEIRA (PPGL-UNEMAT) ${ }^{1}$ \\ Jocineide MACEDO-KARIM (PPGL-UNEMAT) ${ }^{2}$
}

\begin{abstract}
Resumo: Considerando a importância e diversidade comunicativa da mídia virtual, este trabalho pauta-se em observar como questões ligadas à variação linguística são abordadas pela imprensa. Visto que comumente assuntos ligados à linguagem é pauta para jornalistas. Assim, neste trabalho temos como objetivo de pesquisa, não só o de observar o comportamento da imprensa em relação a assuntos sobre a variedade linguística, mas também compreender o modo como a linguagem vêm sendo abordada. Para tanto, buscamos embasamento teórico nos estudos da Sociolinguística, observar o quanto, é necessário, que as variações sejam vistas como constituintes da língua, consideradas e levadas para reflexões nos meios de comunicação em que, muitas vezes, desconsideram as variantes e propagam preconceitos linguísticos. Ao promover esse tipo de discriminação, os profissionais da imprensa vão contra ao que determina o Código de Ética do Jornalista.
\end{abstract}

Palavras-chave: Sociolinguística. Preconceito Linguístico. Variação Linguística. Mídia Virtual.

Abstract: Considering the importance and communicative virtual media diversity, this work is guided in to observe how the press addresses linguistic variation issues. Since commonly issues related to language is the agenda for journalists. In this work, we aim to research, not only to observe the behavior of the press in relation to subjects on the linguistic variety, but also understand the way the language are being addressed. To this end, we seek theoretical basis of Sociolinguistic studies, observe how it is necessary, that the variations are seen as constituents of language, considered and taken to reflections in the media in which often disregard the variants and propagate linguistic biases. To promote this type of discrimination, the professionals of the press run counter to what determines the code of ethics of journalist.

Keywords: Sociolinguistics. Linguistic Prejudice. Linguistic Variation. Virtual Media.

\section{Introdução}

\footnotetext{
${ }^{1}$ Mestranda do Programa de Pós-Graduação Stricto Sensu em Linguística/UNEMAT (2017), Universidade do Estado de Mato Grosso, campus de Cáceres. Bolsista CAPES-FAPEMAT. E-mail: raycruzandressa@gmail.com.

2 Professora Doutora em Linguística do Departamento de Letras e do Programa de Pós-Graduação Stricto Sensu em Linguística/UNEMAT/Cáceres - Coordenadora do projeto de pesquisa: A variação linguística em comunidades quilombolas da Região Centro Oeste do Brasil. E-mai: jocineidekarim@ yahoo.com.br.
} 
A história já provou que a língua é instrumento de poder em vários aspectos, entre alguns exemplos, temos a história das colonizações, como a do Brasil, aos povos dominados é imposta a língua do dominador, em resumo as línguas humanas são muito mais do que instrumentos de comunicação, são, além disso, "reflexo da cultura de um povo", "mecanismos de identidade" (SCHERRE, 2005, p. 10). Diante disso, as variações ocorrem seguindo, também o mesmo rumo das mudanças sociais. Nessa perspectiva, nota-se que a mídia virtual enquanto veículo de comunicação e instrumento de poder mostra-se também como importante divulgadora de valores e ideologias linguísticas, propagando na sociedade afirmações que nem sempre condizem com a realidade linguística.

Assim, observamos que a imprensa quase sempre tem algo a dizer a respeito da linguagem, em particular a língua portuguesa, sendo comumente pauta para publicações. Desse modo, a nossa inquietação inicial cresce a partir do momento em que notamos o meio virtual cada vez mais amplo e acessível, abarcando novas possibilidades de comunicação. Por exemplo, nas revistas online, saímos de um contexto impresso e passamos para um novo espaço, mais dinâmico, acessível e muito mais rápido.

E, como a linguagem quase sempre é assunto para os colunistas (jornalistas) propomos neste trabalho de pesquisa observar de que modo à imprensa aborda questões relacionadas à fala. Contudo, sabemos que esses profissionais da mídia foram formados (assim como nós) por um sistema em que tentam impor a norma culta como se ela fosse de fato comum a todos os brasileiros.

Assim, para observarmos essas questões selecionamos, como amostra, uma matéria da coluna carreira assinada pela colunista Camila Pati, da conceituada revista online Exame.com.

O jornalista tem na língua o seu instrumento de trabalho. Além de tratá-la com respeito, o jornalista deve preservar a dignidade do leitor, inclusive no que diz respeito à língua. Apesar de ser, por seu caráter político, um instrumento de poder, a língua não deve ser usada como um aparelho de opressão e discriminação social. É o que prega o Código de Ética do Jornalista.

Assim nós pretendemos com este trabalho contribuir para que as pessoas comecem a questionar as noções de certo e de errado que circulam na nossa sociedade e que são reproduzidas pelos meios de comunicação. Principalmente, oferecer argumentos a favor da aceitação de muitas formas linguísticas que já estão incorporadas ao português brasileiro.

\section{A imprensa virtual: EXAME.COM}


A comunicação sempre se fez presente, em qualquer período da evolução humana. Grosso modo, podemos destacar algumas manifestações de comunicação durante a evolução dos seres humanos como a arte rupestre (arte em rochas) uma das primeiras manifestações de comunicação do homem ou os mensageiros da idade média que levavam as notícias sobre guerras de um reino para outro. Assim, com o crescente desenvolvimento do homem veio junto à necessidade de especializar o modo de se comunicar, de transmitir informações.

Contudo, o grande salto da comunicação foi com a revolução digital que trouxe um novo veículo para transmitir informações, a internet, que se configura como ferramenta poderosa na relação mídia, imprensa e sociedade.

Através da web, temos um novo espaço, mais amplo e livre nos quais novos profissionais da escrita aparecem, como colunistas e blogueiros, que buscam principalmente estabelecer canais de comunicação com seus públicos. Um dos canais possíveis são as revistas online, saímos da revista impressa para um campo virtual mais acessível.

Esta revolução digital transformou e vem modificando a forma de se fazer jornalismo, seja nas redações ou nas assessorias de imprensa. A partir da internet e sua rapidez incomparável, há uma busca implacável por marcar presença na mídia, mesmo que essa presença na mídia seja com notícias e publicações equivocadas.

Assim, a nossa indagação inicial é verificar como essa mídia online que vem ocupando o espaço da mídia impressa, trata de questões relacionadas ao falar do brasileiro. O que não falta nesse espaço virtual são canais como, blogs e revistas tratando de questões sobre língua portuguesa falada no Brasil. No entanto o que nos chamou atenção foi à revista online EXAME.COM. Para sermos mais específicos a revista EXAME.COM é um site que ostenta o título de principal fonte online sobre negócios no país. Seu foco se estende a economia, mercados financeiros, tecnologia, marketing, gestão, meio ambiente, pequenas empresas, carreira e finanças pessoais.

\section{O Código de Ética do jornalista}

Conforme Marques (2016), para compreendermos o que é ética profissional, buscamos passar pela etimologia da palavra ética. O termo é proveniente do grego, éthos, que significa "propriedade do caráter". Dessa forma, ética profissional é um conjunto de regras que norteiam o comportamento dos indivíduos durante o exercício de seu ofício. Como resultado, têm-se os 
códigos de ética e conduta, que são elaborados pelos conselhos e federações que fiscalizam as profissões e pelas empresas que os contratam como prestadores de serviços.

A carreira de jornalista é considerada importante para a formação da opinião social e para os questionamentos das situações do cotidiano, exige, devido à sua complexidade e alto grau de envolvimento com inúmeras questões polêmicas, um documento moral regulamentador que assegure a estes profissionais da comunicação a manutenção de seus direitos e o cumprimento dos seus deveres.

Tudo aquilo que o jornalista escreve, deve partir de uma noção de importância: o que o público considera relevante, o que a população precisa saber. Seja no âmbito local, nacional ou internacional, esse deve ser um dos pontos de maior atenção, não apenas pela questão se o jornal ainda for um produto que necessita da valorização dos seus clientes, mas porque os veículos jornalísticos carregam em si a "missão" de informar corretamente e levar ao público aquilo que eles não têm acesso completo.

Outro aspecto que devemos mencionar é sobre o avanço tecnológico e o surgimento de sistemas facilitadores de acesso e criação de conteúdo através da internet, a ética jornalística passa por transformações estruturais, em busca de delimitar os deveres sociais e morais que diferenciam o jornalista dos demais produtores, que agora também exercem funções que em outros tempos eram reservadas apenas aos profissionais da área.

Assim, o que nos interessa destacar neste código é o capítulo III, que aborda sobre a responsabilidade do jornalista como profissional. Assim o Art. XVII determina: "preservar a língua e a cultura do Brasil, respeitando a diversidade e as identidades culturais" (FENAJ, 2007, p. 3).

Desse modo o código de ética do jornalista, trata não só da responsabilidade do profissional com a língua, mas sobre o respeito ao falante, pois a língua faz parte de nós, é parte integrante de nosso ser social e biológico. Assim desconsiderar as variações da língua é como desconsiderar o próprio falante.

Contudo, Mesmo que bem intencionadas, as mudanças no Código de Ética dos jornalistas não puderam ir muito além ao âmbito da responsabilidade deste profissional, pois, diferente de outras profissões, os jornalistas mesmo que causem o pior dos prejuízos morais, por exemplo - não correm o risco de perder seus registros profissionais por agirem de forma antiética. As sanções chegam, no máximo, a uma advertência pública ao profissional. 


\section{Preconceito linguístico: mídia virtual}

Toda forma de preconceito é sutil. Além de velada, é muitas vezes irracional e infundada. E nos tempos em que vivemos, com tanta diversidade, é difícil assumir-se preconceituoso.

O preconceito linguístico é do mesmo modo marcado pelas suas sutilezas. O autor Marcos Bagno, nos apresenta a raiz desse mal, que nasceu há 2.500 anos quando os primeiros estudiosos da língua passaram a associar a ideia de língua culta à escrita literária. Desse modo, Bagno defende que:

Essa é uma tradição que começou por volta do século III a.C., entre os filósofos e filólogos gregos, quando foi criada a própria disciplina batizada de gramática. Aliás, sintomaticamente, a palavra gramática, em grego, significava, na origem, 'a arte de escrever'. Ao se interessar exclusivamente pela língua dos grandes escritores do passado, ao desprezar completamente a língua falada (considerada 'caótica', 'ilógica', 'estropiada'), e também ao classificarem a mudança da língua ao longo do tempo de 'ruína' ou 'decadência', os fundadores da disciplina gramatical cometeram um equívoco que poderíamos chamar de 'pecado original' dos estudos tradicionais sobre a língua. Foram eles e seus seguidores, de fato, qufe plantaram as sementes do preconceito lingüístico, que iam dar tantos e tão amargos frutos ao longo dos séculos seguintes. Foram eles que sacralizaram na cultura ocidental o mito que existe ‘erro' na língua, principalmente na língua falada (BAGNO2003, p.43).

O preconceito linguístico é talvez o mais forte e mais enraizado e menos conhecido que os outros tipos de discriminação. Isso porque não há leis que punam os agressores e não há conscientização da gravidade do problema. Assim, o desconhecimento da discriminação leva a questionar se o preconceito linguístico realmente existe ou se é exagero de alguns sociolinguistas. 
Contudo, alguns puristas $^{3}$ insistem em fundamentar-se em na análise das características linguísticas, para estabelecerem o que é "certo" ou "errado" na língua falada. Para a linguística, o conceito de erro é algo relativo e se aplica somente às construções gramaticais. Em contrapartida, a Sociolinguística adota o conceito de adequação, para essa ciência, "certo" é saber organizar uma frase que os outros falantes entendam a mensagem transmitida.

A principal raiz do problema dos preconceitos linguísticos é o que transmite a ideia de que os brasileiros falam errado o português. A partir desse preconceito surgem todas as ramificações sobre "problemas" de concordância e pronúncia, "erros" de colocação pronominal, "falhas" no processo de conjugação dos verbos.

Sobre a avaliação social das variedades linguísticas, Alkmim, afirma:

[...] os julgamentos sociais ante a língua - ou melhor, as atitudes sociais - se baseiam em critérios não linguísticos: são julgamentos de natureza política e social. Não é casual, portanto que se julgue "feia" a variedade dos falantes de origem rural, de classe social baixa, com pouca escolaridade, de regiões culturalmente desvalorizadas. Por que se considera "desagradável" o $r$ retroflexo, o chamado $r$ caipira, presente em realizações como "porta"? Afinal, a mesma articulação retroflexa ocorre em palavras do inglês com "car", (carro), que ninguém sente como "feia". Em resumo: julgamos não a fala, mas o falante, e o fazemos em função de sua inserção na estrutura social. (ALKMIM2004, p. 42)

E o que não falta são profissionais que atuam na área jornalística para apontar os "problemas" que segundo eles muitos brasileiros possuem em relação à pronúncia do português. Esses jornalistas puristas, nos parece tocados e dispostos a defender de qualquer modo a língua nacional e de tão empolgados na sua missão, alguns deles acabaram por confundir as duas coisas e passaram a pregar gramática no lugar de língua e vice-versa. Essa grande confusão, como explicaremos em seguida, fez com que a missão fosse cumprida ao contrário, desprestigiando os falantes, em vez de exaltar e preservar a língua nacional.

\footnotetext{
${ }^{3}$ Conforme o autor Marco Bagno, "A qualificação de purista é atribuída àquela pessoa que defende a "pureza" da língua contra todas as formas inovadoras, que são sempre consideradas como sinais de "decadência", "corrupção" e "ruina", não só da língua como também muitas vezes, dos valores morais da sociedade" (2009, p.30). 
O que torna esse desserviço ainda mais grave é o fato de provocar uma discriminação em relação aos falantes da língua e, por se tratar de uma forma de preconceito, fere ainda mais o Código de Ética (1987 p.1-2):

Art. 9 - É dever do jornalista:

e) Opor-se ao arbítrio, ao autoritarismo e à opressão, bem como defender os princípios expressos na Declaração Universal dos Direitos do Homem.

Art. 10. O jornalista não pode:

d) Concordar com a prática de perseguição ou discriminação por motivos sociais, políticos, religiosos, raciais, de sexo e de orientação sexual.

Art. 14. O jornalista deve

b) Tratar com respeito a todas as pessoas mencionadas nas informações que divulgar. (Grifos nossos)

Assim, gostaríamos de observar como essas determinações são descumpridas. Para tanto retiramos um excerto do nosso corpus de análise, o qual se encontra na matéria "10 palavras que muita gente pronuncia errado” escrita pela colunista, Camila Pati.

Figura 1. Abertura da matéria: 


\section{EXAME.com \\ executivo_boca (Gettylmages) \\ São Paulo - A nossa língua falada é responsável por nos deixar algumas vezes em situações constrangedoras. Isto se deve ao simples fato da sua complexidade não se ater somente às minuciosidades gramaticais, mas também às particularidades da língua falada. \\ Muito se vê sobre erros gramaticais, verdadeiros atentados à nossa brava língua portuguesa, mas pouco se fala dos disparates da língua falada. \\ 0 português proferido e admirado mundialmente é responsável por situações vexatórias e em alguns casos hilárias.}

Fonte: Revista Exame.com ${ }^{4}$

No trecho da matéria em que a colunista afirma que "Muito se vê sobre erros gramaticais, verdadeiros atentados à nossa brava língua portuguesa, mas pouco se fala dos disparates da língua falada." (Grifos nossos) é interessante mencionarmos que a língua não é propriedade do indivíduo, mas da comunidade (é algo social). O conceito de mudança é visto como "um processo contínuo e o subproduto inevitável da interação linguística" (WEINREICH, LABOV e HERZOG, 2006 [1975], p. 87 e 139), ou seja, a dinâmica interna da língua produz mudança linguística.

Pois, em toda língua existe um fenômeno chamado variação, ou seja, nenhuma língua é falada do mesmo jeito em todos os lugares, assim como nem todas as pessoas falam a própria língua de modo idêntico. Não podemos tentar criar uma língua falada "artificial” e reprovando como "erradas" as pronúncias resultantes das forças internas que governam os idiomas.

Contudo, como podemos ver a colunista desconhece as variações linguísticas existentes em nossa língua. Então não se pode dizer que "O português proferido e admirado mundialmente é responsável por situações vexatórias e em alguns casos hilárias." a autora desconsidera o conceito de variação, pois trata tudo o que destoa da norma padrão como erro e delito, como é possível perceber pelo uso dos termos atentados, disparates, situações vexatórias.

${ }^{4}$ Disponível em: www.revista online: Exame.com/Coluna Carreira 
Para esclarecermos melhor sobre a variedade linguística, apoiamo-nos em Aguilera (2009), que nos direciona para a ideia de que a variedade linguística consiste em um traço definidor da identidade do grupo (etnia, povo) e desse modo, qualquer atitude em relação aos grupos com determinada identidade pode tratar-se de uma reação às variedades usadas por esse grupo ou aos indivíduos usuários dessa variedade, uma vez que normas e marcas culturais dos falantes transmitem ou se consolidam através da língua, atualizada na fala de cada indivíduo.

Deste modo, podemos notar que a língua assume a função de segregar aquilo que é esperado, daquilo que não é esperado ou inadequado em relação às normas determinadas pela gramática normativa utilizada por uma comunidade considerada prestigiada dentro da sociedade.

Assim, após as afirmações (equivocadas) da autora sobre a fala dos brasileiros, sobre o quanto nossa língua é complicada e os demais termos que ela utilizou para caracterizar nosso idioma, ela segue com o "foco" da matéria em que seriam 10 palavras quais segundo ela muita gente pronuncia errado. Contudo, destacamos abaixo duas palavras que a jornalista destaca inicialmente:

(1) “Questão - Para muitos "cuestão”. Se o ditongo ue estivesse acompanhado da extinta trema, justificaria a pronúncia!

(2) Subsídio - Quando escutamos uma autoridade pronunciar com o som de Z "subzídio", acredito que o zumbido provocado pela gafe é estarrecedor para muitas pessoas. Mas eu sou capaz de insistir que muitas ainda pronunciam de forma equivocada, ou seja, "subzidio" ao invés de "subcídio". Recapitulando, subsídio é um substantivo masculino que entre os seus significados estão: apoio, recurso, reserva, reforço entre outros.

Exemplos: Enviarei alguns subsídios para a sua tese.

Criou-se uma reserva de subsídio destinada aos menos favorecidos. (PATI, 2014, p. 2)

Sobre as duas palavras destacadas pela autora é válido dizer, que além de equivocada a autora está desinformada. Por exemplo, a palavra questão pode ser pronunciada no mínimo

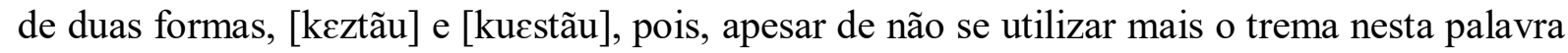


devemos lembrar que o acordo ortográfico de 1990 é meramente ortográfico, não afetando a língua falada, sendo assim, continuam válidas - como se vê na indicação ortoépica do Houaiss, ou em uma simples pesquisa no Vocabulário Ortográfico da Academia Brasileira de Letras.

Por fim, para os puristas a quem possa incomodar a informação de que a pronúncia "qüestão" também é admitida, cabe recordar: a palavra nos veio do latim quaestiōne, e, em latim, o "u" era obrigatoriamente pronunciado - como ainda o é em três de nossas línguas mais próximas: o galego, o espanhol e o italiano." (DICIONARIO E GRAMATICA.COM, 2016, p.3).

Portanto, etimologicamente, não há dúvida: a pronúncia [kuعstãu] é no mínimo tão legítima quanto à alternativa sem o "u“.

Adiante, a jornalista Camila Pati cita a palavra Subsídio, e argumenta que "Quando escutamos uma autoridade pronunciar com o som de Z "subzídio”, acredito que o zumbido provocado pela gafe é estarrecedor para muitas pessoas." Embora a forma "correta" apontada pelo sistema ortográfico é a de que o $s$ apenas tem som de $z$ entre duas vogais, mas permanece com som de $s$ entre uma consoante e uma vogal. Contudo há casos como desta palavra subsídio, que começam pouco a pouco a despontar, embora ainda sejam repelidos pela fala culta. Pois, conforme o professor Claudio Moreno:

A pronúncia do $\mathbf{S}$ em subsolo, subseqüente, subserviente, subsistema aponta para a pronúncia /subcídio/, /subcidiar/. É assim que as gramáticas e os dicionários recomendam, e assim devemos usar na fala cuidada, consciente, de banho tomado e de cabelo penteado. É impossível negar, contudo, que a tendência natural dos falantes é dizer /subzídio/. Eu diria que $95 \%$ das pessoas que usam o vocábulo preferem o som de /z/, e isso é muito significativo, não pela força da estatística, mas porque revela a atuação de alguma força concreta e irresistível" (MORENO, 2016, p. 2).

Os estudiosos se dividem, argumentam, explicam e cabe a nós, falantes da língua portuguesa, escolher uma ou outra proposta.

No entanto o que nos inquieta é que, com que base à autora aborda questões de uso da linguagem? Quando falamos em certo ou correto em relação à fala, devemos antes compreender 
que a língua não está pronta e acabada. A forma com que ela aborda este assunto é como se a língua tivesse passado por transformações no passado, mas que, agora as regras estão fixas para sempre. Mas isso é uma ilusão, pois, enquanto tiver gente falando uma língua, ela vai sofrer variações e mudanças incessantemente.

Pois, as diferentes maneiras de pronunciar criam um espaço propício à mudança. $\mathrm{O}$ linguista, Faraco (2008) nos direciona para uma concepção de que a mudança emerge da heterogeneidade. Isto é, fenômenos típicos de algumas variedades acabam por ser adotados pouco a pouco pelos falantes de outras variedades, resultando em alterações na pronúncia ou na estrutura dos enunciados destas últimas. E esse é um processo contínuo, impossível de ser estancado. Contudo, há quem não perceba a grandeza e a dinamicidade da língua e que acredita que ela pode ser reduzida a regras.

Para Labov (2008), os valores sociais atribuídos a duas formas linguísticas (como a colunista apresenta), uma padrão ou conservadora e outra inovadora, frequentemente significam também uma oposição entre valores sociais. Tais valores sociais podem alcançar o nível de conscientização social e se tornarem estereótipos, sujeitos à correção social irregular ou, então, podem permanecer abaixo do nível como marcadores inconscientes.

Assim, para fechar à matéria a colunista cita as palavras restantes, em uma tabela de duas colunas entre certo e errado. Vejamos as palavras na figura 2 que segue.

Figura 2: Alguns exemplos práticos:

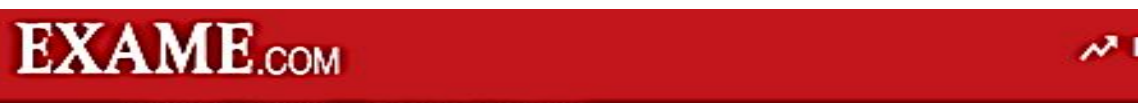

Logo abaixo, acrescento mais alguns exemplos práticos. Espero que tenham gostado!

\begin{tabular}{|c|c|}
\hline Incorreto & Correto \\
\hline Pertubar & Perturbar \\
\hline Entertido & Entretido \\
\hline Ciclo vicioso & Círculo vicioso \\
\hline Jüniors & Juniores \\
\hline Sêniors & Seniores \\
\hline Aerosol & Aerossol \\
\hline Espinho de peixe & Espinha de peixe \\
\hline
\end{tabular}

Fonte: Revista online: Exame.com. 
O que podemos visualizar desses exemplos práticos, é que o verdadeiro problema, a verdadeira questão social implicada nisso tudo não tem a ver com o fato de se usar essa regra e não aquela. Tem a ver, com o uso social perverso que se faz do domínio desse aparente saber,

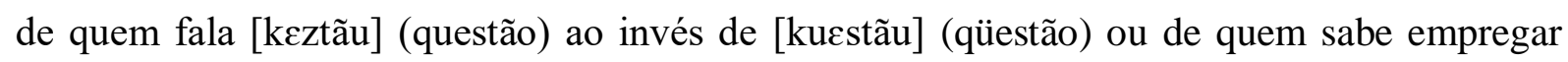
corretamente regras gramaticas em uma fala e quem não sabe está praticando um atentado contra a nossa língua portuguesa. São discursos como estes, muitas vezes não evidente, oculto na atitude de quem se vale do seu conhecimento da gramática normativa que geram uma falsa ideia de superioridade intelectual e que resulta consequentemente em exclusão social, pois quem não sabe utilizar "corretamente” tal pronúncia, possuí diferentes variações linguísticas esta consequentemente fora de um padrão linguístico que uma pequena (mas poderosa) parcela da sociedade impõe.

Esses exemplos práticos de pronúncia correta ou errada, não são ruins. Contudo o que podemos ver diante de tudo que já foi dito, até agora, é que na verdade, a normatização do que é correto e do que não é correto no uso da língua é resultado das relações econômicas e de poder, e dessa normatização resulta a existência de variedades de prestígio e variedades desprestigiadas na sociedade.

\section{A língua não pode servir para exclusão social}

Antes de qualquer coisa, é necessário frisarmos que do ponto de vista da Linguística e da Sociolinguística, todos os falantes de língua portuguesa dominam a oralidade, pois crescem e falam a língua desde muito cedo, quando ainda criança, por diversos meios, diálogos em casa e na comunidade que os cercam, ou por rádio, televisão e etc., seja por histórias que ouvem.

Conforme Scherre (2005, p.9) "Falar é como andar. Acontece naturalmente, da mesma forma, nas mesmas faixas etárias, em qualquer parte do planeta terra, independente de raça, de cultura, de cor, de gênero e de ensino formal. Basta que sejamos seres humanos".

Portanto, é importante reconhecermos que a língua faz parte de nós, nasce conosco e não deve ser usada como instrumentos para exclusão.

Neste contexto é interessante o que Calvet (2002, p. 65) nos mostra, a relação entre o falante e sua língua nunca é neutra. Ele argumenta que "existe todo um conjunto de atitudes, de sentimentos dos falantes para com suas línguas, para com as variedades de línguas e para com 
aqueles que as utilizam”. Não é à toa que geralmente as pessoas são julgadas pelo seu modo de falar.

Reconhecemos que conhecer a riqueza do nosso vocabulário, a história da língua, a tradição gramatical, o potencial da nossa linguagem, tudo isso é muito bom e necessário. Só não podemos aceitar transformarem tudo isso em um tipo de instrumento autoritário de repressão e exclusão social.

\section{Breves Considerações Finais}

Procuramos demonstrar neste artigo o modo como a imprensa trata de questões ligadas a linguagem, de modo que consequentemente afeta o falante, pois vale ressaltar que a língua faz parte do ser humano, não é algo que está fora de nós, mas está presente em nosso ser biológico e social.

Pois, a mídia e a imprensa unidas possuem grande poder, a cada dia podemos ver notícias e diversos conteúdos propagarem-se pelo mundo em questão de segundos. A revista digital, Exame.com é um exemplo disso, uma revista reconhecida mundialmente, pelo conteúdo e seus colunistas. Seu conteúdo chega diariamente a milhares de pessoas. Sendo assim, justifica nossa escolha para tal análise.

Desse modo, a constatação da existência de preconceito linguístico na imprensa virtual é indício suficiente para afirmar que há um desrespeito ao indivíduo leitor no que diz respeito à língua. A tarefa de preservar a língua determinado pelo artigo 17 do Código de Ética dos Jornalistas parece ter sido assimilada de modo equivocado por esses profissionais midiáticos. E, é possível dizermos que o preconceito linguístico é simplesmente uma crença de conotação negativa, em relação ao falar do outro, fundada em um preconceito social prévio disseminado pelos grupos sociais e pelos meios de comunicação de massa.

A língua por ser um instrumento de poder, pode ser usada também como instrumento de opressão. É o que se faz quando propagam por aí que população de um país não domina a própria língua ou ainda dizer o quanto nossa língua é muito complexa, excluindo membros de qualquer contexto social.

E, é claro que ninguém é obrigado a adotar as variações da língua. Qualquer um de nós pode optar por ser conservador no tocante a língua. Contudo, o fato de ter uma postura conservadora não permite condenar os que usam formas inovadoras. 


\section{REFERÊNCIAS}

AGUILERA, V. A. Crenças e atitudes linguísticas: o que dizem os falantes das capitais brasileiras. Estudos Linguísticos (São Paulo), v. 2, p. 105-112, 2008. Disponível em: http://www.gel.org.br/estudoslinguisticos/volumes/37/EL_V37N2_11.pdf Acesso em: 12 de junho de 2016.

ALKMIM, Tânia Maria. Sociolingüística. In: MUSSALIN, F.; BENTES, A.C. (Org.). Introdução à linguística - domínios e fronteiras. São Paulo: Cortez, 2002.p. 40.11 Cf.

CALVET, Louis-Jean. Sociolinguística, uma introdução crítica. Trad. Marcos Marcilio. São Paulo: Parábola, 2002.

BAGNO, Marcos. A norma oculta: língua \& poder na sociedade brasileira. São Paulo: Parábola Editorial, 2003.

Não é errado falar assim! Em defesa do Português Brasileiro. São Paulo: Parábola Editorial, 2009.

CHRISTOFOLETTI, Rogério. Código de ética dos jornalistas: Revisão bem-vinda, mas insuficiente. $2007 . \quad$ Nov. Disponível em: http://www.intervozes.org.br/direitoacomunicacao/?p=19691 Acesso em: 13 dezembro. 2016. Dicionário de gramatica. Com gramática. Ortografia. Lexicologia. História da língua portuguesa. Suas variantes, evoluções, rumos e futuro. Existe qüestão? 'kestão' ou 'cuestão', a pronúncia de questão. Disponível em: https://dicionarioegramatica.com.br/tag/como-e-apronuncia-da-palavra-questao/. Acesso em: 14 jan. 2017.

FARACO, Carlos Alberto. Norma culta brasileira: desatando alguns nós. São Paulo: Parábola Editorial, 2008. 
FENAJ FEDERAÇÃO NACIONAL DOS JORNALISTAS. Código de Ética dos Jornalistas Brasileiros - (1985/2007). Disponível em: http://fenaj.org.br/codigo-de-etica-dos-jornalistasbrasileiros-19852007/- código de ética>. Acesso em: 28 nov. 2016.

MARQUEZ, José Roberto. Portal IBC: O que é código de conduta e ética profissional? Março, 2016. Disponível em: http://www.ibccoaching.com.br/portal/comportamento/o-quecodigo-conduta-etica-profissional/ Acesso em: 18 maio. 2016

MORENO, Claudio. Sua língua: Transar, obséquio e subsídio. Disponível em: http://sualingua.com.br/2009/05/18/transar-obsequio-e-subsidio/ Acesso em: 13 jan. 2016

PATI, Camila. 10 Palavras que muita gente pronuncia errado. Exame.com, São Paulo, 18, fev.2014. Disponível em: https://exame.abril.com.br/carreira/10-palavras-que-muita-gentepronuncia-errado/\#. Acesso em: 14 jan. 2016.

SCHERRE, Marta. Doa-se lindos filhotes de poodle: variação linguística, mídia e preconceito. São Paulo: Parábola Editorial, 2005.

LABOV, William. Padrões sociolinguísticos. São Paulo: Parábola, [1972] 2008.

WEINREICH, Uriel; LABOV, William e HERZOG, Marvin. Fundamentos empíricos para uma teoria da mudança linguística. São Paulo: Parábola, 2006 [1975]. 